\section{A COMISSÃO \\ INTERAMERICANA DE \\ DIREITOS HUMANOS E O \\ BRASIL}

\section{Paulo Sergio Maluf Barroso}

\section{Sumário}

1 Introdução. 2 Comissão Interamericana de Direitos Humanos. 2.1 O que é a Comissão Interamericana de Direitos Humanos. 2.2 Como entrar em contato com a Comissão Interamericana de Direitos Humanos. 2.3 Breve histórico do Sistema Interamericano de Direitos Humanos. 2.4 Funções e atribuições da Comissão Interamericana de Direitos Humanos. 3 Direitos Humanos e Direitos Fundamentais. 3.1 Diferença entre direitos humanos e direitos fundamentais. 3.2 Proteção Internacional dos Direitos Humanos. $4 \mathrm{O}$ Brasil diante do Sistema Internacional de proteção dos Direitos Humanos. 4.1 A redemocratização do Brasil. 4.2 O Brasil e os tratados internacionais de direitos humanos. 4.3 A Justiça Penal Internacional. 5 Relatórios na Comissão Interamericana de Direitos Humanos. 5.1 Introdução. 5.2 Relatório n. ${ }^{\circ}$ 38/02 - Damião Ximenes Lopes - Petição 12.237. 5.3 Relatório n. ${ }^{\circ}$ 21/03 - Eldorado de Carajás - Petição 11.820. 5.4 Relatório n. ${ }^{\circ} 40 / 03-42^{\circ}$ Distrito Policial - Parque São Lucas, São Paulo. Conclusão.

\section{Resumo}

O presente artigo, que intitulamos " $\mathrm{A}$ Comissão Interamericana de Direitos Humanos e o Brasil", apresentado como requisito para avaliação na Disciplina Sistema Internacional de Proteção aos Direitos Humanos, está sendo para nós um presente, pois é possível o entendimento dos instrumentos interamericanos de proteção aos Direitos Humanos.

Optamos pela apresentação da estrutura da Comissão Interamericana de Direitos 
208 Humanos, suas funções, o modo de provocar sua atuação e um breve histórico sobre ela. Sem nos esquecermos de que se trata de um artigo, entendemos cabível trazer à tona algumas diferenças sobre o conceito de Direitos Humanos e Direitos Fundamentais, bem como, a aplicação de normas no Brasil. Impossível pensarmos em Direitos Humanos em nosso País sem falarmos, ainda que com parcimônia, no processo de redemocratização vivido no Brasil nos últimos vinte anos.

Finalmente, trouxemos ao nosso estudo, alguns casos do Brasil apreciados na Comissão Interamericana de Direitos Humanos: Eldorado de Carajás, $42^{\circ}$ Distrito Policial de São Paulo - Parque São Lucas e o Caso de Damião Ximenes Lopes, que custou condenação ao Brasil.

\section{Palavras-chave}

Comissão Interamericana de Direitos Humanos. Sistema Interamericano de Direitos Humanos. O Brasil e os Tratados Intenacionais de Direitos Humanos.

\section{Introdução}

We opted to present the Inter-American Commission on Human Rights structure, its functions, the way to instigate its action and a brief history about it.

Without forgetting the fact this is an article, we believe it to be interesting to underscore some of the differences regarding Human Rights and Fundamental Rights, as well as the application of norms in Brazil.

It is impossible for us to think of Human Rights in our country without mentioning, albeit briefly, the redemocratization process experienced in Brazil over the past twenty years.

In conclusion, we included in our study some cases from Brazil that were studied by the Inter-American Commission on Human Rights: Eldorado de Carajás, 42nd São Paulo Police District - São Lucas Park and the Case of Damião Ximenes Lopes, which resulted in Brazil's condemnation.

\section{Key words}

Inter-American Commission on Human Rights. Inter-American Human Rights System. Brazil and International Human Rights Treaties.

Iniciamos esse nosso trabalho, fazendo a mesma indagação feita pelo grande filósofo italiano, o saudoso Norberto Bobbio:

O tema dos direitos do homem, que foi imposto à atenção dos soberanos pela Declaração de 1789, não será hoje mais atual do que nunca? Não é um dos grandes temas, juntamente com o da paz e o da justiça internacional, para os quais são arrastados irresistivelmente, queiram-no ou não, povos e governos? Assim como as Declarações nacionais foram o pressuposto necessário para o nascimento das democracias modernas, a Declaração Universal dos Direitos do Homem não será talvez o pressuposto daquela democratização do sistema internacional da qual dependem o fim do sistema tradicional de equilíbrio, no qual a paz é sempre uma trégua entre duas guerras, e o início de uma era de paz estável que não tenha mais a guerra como alternativa? ${ }^{1}$

Sabemos que após o 11 de setembro, o mundo não foi mais o mesmo, pelo menos é o que afirmam os editoriais dos diversos jornais no mundo, inclusive no Brasil, apesar

\footnotetext{
${ }^{1}$ NOBBIO, Norberto. A era do direito. 2 tiragem. Apresentação de Celso Lafer. Rio de Janeiro: Campus. p. 117. 
de que em nossa cultura os jornais não conseguem uma grande penetração nas chamadas

"massas populares", ficando restrito a um número pequeno de leitores, se comparado com o número de habitantes de nosso país e o número de assinantes e leitores assíduos dos diários escritos.

Faço essa ressalva, pois nunca devemos nos esquecer da realidade em que vivemos, sob pena de escrevermos e falarmos para as pedras, pois estaremos totalmente dissociados do mundo real, vivendo em um mundo do "deve ser".

Não é o caso, mas se fossemos ser justos em nosso pensamento, aqui trazido, deveríamos tecer diversas considerações no que tange ao fato de estarmos escrevendo no contexto de uma universidade privada (Unifieo), em uma realidade urbana (Osasco) no maior e mais rico estado da federação: São Paulo, o que sem dúvida não reflete a maioria do Brasil.

Voltando ao pós 11 de setembro, não seria o caso de escrevermos os motivos que levaram aqueles suicidas a matarem um número desconhecido (apenas existem estimativas do número real de mortos) de pessoas inocentes, que sequer conheciam o rosto de seus algozes e vice-versa.

Mas devemos nos lembrar, e isso realmente é importante, que no momento em que pessoas se sentem no direito de jogar aviões contra prédios, trazendo um rastro de morte e sofrimento, somos forçados a reconhecer que o nosso sistema de proteção aos direitos humanos internacionais não estão atendendo às suas funções básicas: falharam.

Digo isso com a convicção de que os terroristas ao se "matarem e matarem" (a repetição é proposital) tinham convicção de que os instrumentos internacionais de solução de conflitos são falhos, e que, portanto têm o direito de utilizarem outros métodos para a solução dos conflitos, inclusive a força.

É incrível que ainda nos assustemos ao olharmos para as cenas dantescas daquela manhã norte-americana (que depois se repetiriam na Espanha), não pela violência, que sempre deverá nos questionar e por que não dizer, envergonhar, porém, pela repetição de tragédias anunciadas.

Quando terminou a Segunda Grande Guerra, ao se abrirem os portões dos campos de concentração, muitos se perguntaram como teríamos coragem de nos olhar após o genocídio perpetuado pelos alemães, e muitos afirmaram que o mundo nunca mais seria o mesmo após os fornos de Auschwitz e Birkenau.

Recentemente o Papa Bento XVI, o austero Papa alemão, de cabelos brancos e envelhecidos no saber e na oração diuturna, visitou a Polônia, terra de seu antecessor João Paulo II, e diante de Auschwitz declarou:

"É estarrecedor para um cristão e para um papa alemão, mas eu não poderia deixar de vir aqui."2

${ }^{2}$ O Estado de S. Paulo, ano 127, 29 maio 2006, n. 14.131. Capa. 

sociedade, principalmente aqueles investidos de função pública, nunca se esqueçam que uma cidade melhor depende do respeito integral e intransigente dos Direitos Humanos, principalmente dos mais simples e menos favorecidos de nossa sociedade.

Confirmando nosso entendimento, transcrevemos pequeno trecho que destaca esse novo olhar que devemos constantemente atualizá-lo:

Após a Segunda Guerra Mundial, o mundo, amedrontado com o poder beligerante das nações e com a iminência de uma guerra nuclear, instituiu a ONU, com o objetivo precípuo de promover a paz entre os povos. Iniciou-se, então, a guerra fria, que perdurou até o colapso da União Soviética. Um dos primeiros frutos da ONU foi a declaração Universal dos Direitos do Homem, proclamada em $1948 .^{3}$

É claro que não devemos, e não podemos, perder a esperança de que o mundo de nossos netos será melhor do que o mundo de nossos avós, pelo menos no que diz respeito aos Direitos Humanos.

Foi pensando nesses problemas que optamos por um artigo simples e prático: escrever sobre a Comissão Interamericana de Direitos Humanos, a sua importância, a sua função e principalmente, como o Brasil tem se comportado diante dela.

\section{Comissão Interamericana de Direitos Humanos}

\subsection{O que é a Comissão Interamericana de Direitos Humanos}

Os dados utilizados nessa pesquisa, em relação à Comissão Interamericana de Direitos Humanos (CIDH) foram retirados da pesquisa no site indicado pela Professora $\mathrm{Dr}^{\mathrm{a}}$ Margareth Anne Leister, que tão brilhantemente ministrou aulas no curso de Mestrado, na disciplina do Sistema Internacional de Proteção aos Direitos Humanos4.

A Comissão Interamericana de Direitos Humanos (CIHD) é uma das entidades do sistema interamericano de proteção e promoção dos direitos humanos nas Américas.

Tem sua sede em Washington, D.C., nos Estados Unidos.

O outro órgão é a Corte Interamericana de Direitos Humanos, com sede em San José, na Costa Rica.

\footnotetext{
${ }^{3}$ SORIANO, Aldir Guedes. Liberdade religiosa no Direito Constitucional e Internacional. São Paulo: Juarez de Oliveira, 2002, p.65. (Prefácio de Celso Ribeiro Bastos. Apresentação de Valério de Oliveira Mazzuoli).

${ }^{4}$ Disponível em: <http://cidh.org/que.htm>. Acesso em: 23 jun. 2006.
} 
A CIDH é um órgão principal e autônomo da Organização dos Estados Americanos (OEA), cujo mandato surge da Carta da OEA e da Convenção Americana sobre Direitos Humanos, e que atua na representação de todos os países membros da OEA.

É composta por sete membros independentes que desempenham suas funções de forma pessoal, que não representam a nenhum país em particular e que são eleitos em Assembléia Geral.

A CIDH se reúne em períodos ordinários e extraordinários de sessões, várias vezes por ano.

\subsection{Como entrar em contato com a Comissão Interamericana de Direitos Humanos}

Na página da CIDH temos o seu endereço, com várias formas de contato:

Comissão Interamericana de Direitos Humanos

1889 F St., N.W., Washington, D.C. U.S.A 20006

E-mail: cidhoea@oas.org

Telefone: (202) 458-6002

Fax: (202) 458-3992

\subsection{Breve histórico do Sistema Interamericano de Direitos Humanos}

Em abril de 1948, a OEA aprovou a Declaração Americana dos Direitos e Deveres do Homem, em Bogotá, Colômbia, o primeiro documento internacional de direitos humanos de caráter geral.

A CIDH foi criada em 1959, reunindo-se pela primeira vez em 1960.

Já em 1961, a CIDH começou a realizar visitas in loco para observar a situação geral dos direitos humanos em países membors, ou para investigar situações particulares.

Desde então realizou 83 visitas a 23 países membros.

Com respeito às suas observações do tipo geral sobre a situação em um país, a $\mathrm{CIDH}$ publica informes especiais (relatórios).

Desde 1965, a CIDH foi autorizada expressamente a receber e processar denúncias ou petições sobre casos individuais e nos quais se alegam violações aos direitos humanos.

Em 1969, foi aprovada a Convenção Americana sobre Direitos Humanos, que entrou em vigor em 1978 e já foi ratificada, até setembro de 1997, por 25 países.

A Convenção define os direitos humanos que os Estados que ratificaram se comprometem internacionalmente a respeitar e dar garantias para que sejam efetivados. 


\subsection{Funções e atribuições da Comissão Interamericana de Direitos Humanos}

São várias funções da CIDH, destacaremos apenas algumas:

- Receber, analisar e investigar petições individuais que alegam violações dos direitos humanos;

- Observar a vigência geral dos direitos humanos nos Estados membros, e quando o considerar conveniente, publicar informes especiais sobre a situação de um Estado em particular;

- Realizar visitas in loco aos países para aprofundar a observação geral e a situação, e para investigar uma situação particular;

- Estimular a consciência dos direitos humanos nos países da América;

- Realizar e participar em conferências e reuniões com autoridades e intelectuais, com o intuito de difundir e analisar temas relacionados com o sistema interamericano dos direitos humanos.

\section{Direitos Humanos e Direitos Fundamentais}

\subsection{Diferença entre Direitos Humanos e Direitos Fundamentais}

Entendemos cabível e essencial, buscarmos diferenciar Direitos Humanos e Direitos Fundamentais, pois, aparentemente são sinônimos, motivo pelo qual transcrevemos um trecho do entendimento de Carla Pinheiro:

Os conceitos de Direitos Humanos e de Direitos e de Direitos Fundamentais são, por vezes, usados indistintamente. Existe também, na doutrina pátria, quem utilize esses dois vocábulos conjuntamente. No contexto do presente livro, é necessário, porém, que se faça uma diferenciação entre esses termos, não somente pela exigência de maior precisão terminológica, mas também pelas conseqüências tanto formais quanto materiais decorrentes de sua utilização diferenciada.

Schmitt afirma que os Direitos Fundamentais, em seu aspecto formal, nada mais são que os Direitos Humanos positivados pela Constituição. Os Direitos Humanos, Menschenrechte, como o próprio nome está a dizer, são os inerentes a todos os seres humanos, sem qualquer discriminação. Já os Direitos Fundamentais, Grundrecbte, são os inerentes a todos os indivíduos que estejam vinculados, de alguma forma, a determinado Estado.

O grau de eficácia que as normas de Direito Fundamental ocupam no âmbito constitucional do Estado é o elemento que 
vai determinar a dimensão desses direitos dentro de determinado ordenamento jurídico. ${ }^{5}$

Portanto, fica evidenciado que os Direitos Humanos são mais abrangentes que os Direitos Fundamentais.

\subsection{Proteção Internacional dos Direitos Humanos}

Desde meados do século XIX, os direitos humanos passaram a ter proteção do Direito Internacional; foi, porém, a Carta das Nações Unidas que iniciou o processo da proteção universal desses direitos, ao dispor em seu art. 55 que a ONU "promoverá o respeito universal aos direitos humanos e às liberdades fundamentais de todos, sem fazer distinção por motivos de raça, sexo, idioma ou religião, e a efetividade de tais direitos e liberdades." Em seguida, surgiram a Declaração Universal dos Direitos Humanos de 1948, o Pacto Internacional de Direitos Civis e Políticos e o Pacto Internacional de Direitos Econômicos, Sociais e Culturais, ambos de 1966"'.

Interessante é o texto abaixo transcrito, dando-nos conta da internacionalização dos direitos humanos:

O movimento de internacionalização dos direitos humanos constitui um movimento extremamente recente na história, surgindo, a partir do pós-guerra, como resposta às atrocidades e aos horrores cometidos durante o nazismo. A era Hitler foi marcada pela lógica da destruição e da descartabilidade da pessoa humana, que resultou no extermínio de 11 milhões de pessoas. O legado do nazismo foi o aparato estatal, na condição de principal delinqüente, condicionar a titularidade de direitos à pertinência a determinada raça - a raça pura ariana. Isto é, se para a concepção jusnaturalista a condição de sujeito de direitos tinha como requisito único e exclusivo a qualidade de ser humano, o legado da barbárie o substitui pela pertinência a determinada raça, negando a determinados grupos a titularidade de direitos básicos.

É neste cenário que se desenha o esforço de reconstrução dos direitos humanos, como paradigma e referencial ético a orientar a ordem internacional contemporânea. Se a $2^{\mathrm{a}}$ Guerra significou a ruptura com os direitos humanos, o Pós-Guerra deveria significar a sua reconstrução.

${ }^{5}$ PINHEIRO, Carla. Direito Internacional e Direitos Fundamentais. São Paulo: Atlas, 2001, p.2223.

${ }^{6}$ PINHEIRO, Carla. Ibidem, p. 56. 

Declaração Universal dos Direitos Humanos, como marco maior do processo de reconstrução dos direitos humanos. ${ }^{7}$.

\section{O Brasil diante do sistema internacional de proteção dos Direitos Humanos}

\subsection{A redemocratização do Brasil}

Talvez para os jovens com menos de 20 anos, falar em democracia pode parecer sem qualquer importância, como se a vida nacional sempre fosse como é hoje: acertos e erros, um Congresso Nacional com bons e maus políticos, protestos, greves.

Porém, quem tem um pouco mais de idade, sabe muito bem que o Brasil mudou muito nos últimos 20 anos, pois passou (e passa) por um processo de redemocratização.

Tudo começou (ou se preferir, terminou) no dia 31 de março de 1964, momento em que os militares deram um golpe de Estado, derrubando o então presidente da república João Goulart, iniciando-se um período de exceção, sendo imposto o general Castello Branco, que depois seria sucedido por Costa e Silva, todos sem a legitimidade do voto popular.

As pessoas que hoje pedem o fechamento das casas legislativas deveriam se lembrar dos períodos sombrios que nossa sociedade atravessou em um passado não distante, quando a primeira providência era fechar o Congresso Nacional. Quem não se lembra daquela fotografia do Legislativo Federal cercado por tropas do Exército?

O período de ditadura se tornou mais áspero a partir de 1968, a partir da edição do Ato Institucional n. 5, dando amplos poderes ao Presidente da República (sem legitimidade, pois era um General imposto pelos golpistas), sendo que o período da presidência do general Médici é considerado pelos historiadores como o mais sombrio de nossa história recente, com casos de execuções sumárias e torturas generalizadas dos opositores do regime militar.

Após o nefasto governo de Garrastazu Médici tivemos a posse de Ernesto Geisel, que deu início a um lento e gradual processo de abertura política, que teve seu aprofundamento no governo seguinte do general João Batista de Oliveira Figueiredo.

Assim sendo, para nos localizarmos, o período militar teve início no dia 31 de março de 1964 e finalizou no dia 15 de março de 1985, com a posse de José Sarney, que assumiu a presidência no lugar de Tancredo Neves, que morreu antes da posse.

\footnotetext{
${ }^{7}$ CENTRO de Estudos da Procuradoria Geral do Estado de São Paulo. Sistema Interamericano de Proteção dos Direitos Humanos - Legislação e Jurisprudência. 2001. p.73.
} 
Por que estamos tratando disso? Simplesmente porque, com a redemocratização, o Brasil passou a ser signatário em vários tratados internacionais referentes aos Direitos Humanos, passando a ser visto com maior seriedade pelos organismos internacionais de proteção dos mesmos.

\subsection{O Brasil e os Tratados Internacionais de Direitos Humanos}

Dentro do que foi exposto anteriormente, transcreveremos trecho da obra de Flávia Piovesan a respeito dos fatos ${ }^{8}$ :

Desde o processo de democratização do País e em particular a partir da Constituição Federal de 1988, o Brasil tem adotado importantes medidas em prol da incorporação de instrumentos internacionais voltados à proteção dos direitos humanos.

O marco inicial do processo de incorporação do Direito Internacional dos Direitos Humanos pelo direito brasileiro foi a ratificação, em $1^{\circ}$ de fevereiro de 1984 , da Convenção sobre a Eliminação de todas as formas de Discriminação contra a Mulher. A partir dessa ratificação, inúmeros outros relevantes instrumentos internacionais de proteção dos direitos humanos foram também incorporados pelo direito brasileiro, sob a égide da Constituição Federal de 1988, que, como já visto, situa-se como marco jurídico da transição democrática e da institucionalização dos direitos humanos no País. Assim, a partir da Carta de 1988, importantes tratados internacionais de direitos humanos foram ratificados pelo Brasil.

\subsection{A Justiça Penal Internacional}

Antes de entrarmos diretamente no estudo de casos concretos da Comissão Interamericana de Direitos Humanos, entendemos relevante traçarmos alguns pontos sobre a Justiça Penal Internacional.

Vejamos:

Durante muito tempo a humanidade sonhou na instituição efetiva de uma Justiça Penal Internacional. Já se pretendeu ver instituído um Tribunal Penal Internacional, de caráter permanente e com jurisdição universal, desde a época que os primeiros grandes atentados à dignidade humana começaram a aparecer no cenário internacional. Hoje este sonho já se tornou realidade.

\footnotetext{
${ }^{8}$ PIOVESAN, Flávia. Direitos Humanos e o Direito Constitucional Internacional. 7. ed. Revista, ampliada e atualizada. São Paulo: Saraiva, 2006, p. 260-261.
} 
À custa de muito sangue derramado durante vários períodos históricos marcantes, conseguiu-se finalmente criar a então sonhada Justiça Penal Internacional. O nascimento do Tribunal Penal Internacional, pelo Estatuto de Roma de 1998, demarca uma nova era na história do Direito Internacional e das Relações Internacionais. ${ }^{9}$

\section{Relatórios da Comissão Interamericana de Direitos Humanos}

\subsection{Introdução}

Ao optarmos pelo tipo de abordagem que estamos fazendo, o fizemos de modo a possibilitar ao leitor uma visão razoável das atividades da CIDH, bem como, uma idéia clara de qual matéria é por ela apreciada.

Durante as proveitosas aulas de Mestrado com a Professora Margareth, pudemos perceber a importância da CIDH e os reflexos advindos do não cumprimento de suas recomendações.

Assim sendo, veremos na seqüência alguns relatórios (de modo resumido) de casos do Brasil, sendo importante destacar alguns detalhes: o primeiro caso (Damião Ximenes Lopes) os autores da violação são agentes do estado (Médico Legista), porém, no caso concreto, no momento da ação/omissão em relação à vítima Damião, não estavam na condição de agentes do Estado, e sim como funcionários da Clínica Médica.

Nos outros dois casos, Eldorado de Carajás e Parque São Lucas, não há dúvidas que os autores das violações contra os Direitos Humanos estavam investidos da condição de agentes estatais.

\subsection{Relatório 38/02 - Damião Ximenes Lopes - Petição 12.23710}

A petição contra a República Federativa do Brasil foi apresentada em 22 de novembro de 1999, pela Sr. ${ }^{a}$ Irene Ximenes Lopes Miranda na CIDH, sendo em tese o prejudicado o Sr. Damião Ximenes Lopes, irmão de Irene, morto dentro das dependências da Casa de Repouso Guararapes, em Sobral, Estado do Ceará.

Alegou a Sr. ${ }^{a}$ Irene que seu irmão foi internado na referida Casa de Repouso, para receber tratamento psiquiátrico, uma vez que era portador de doença mental e dois dias

\footnotetext{
${ }^{9}$ MAZZUOLI, Valério de Oliveira. Tribunal Penal Internacional e o Direito Brasileiro. São Paulo: Premier Máxima, 2005, p. 15.

${ }^{10}$ Disponível em: < http://www.cidh.org/annualirep/2202port/brasil12237.htm>. Acesso em: 23 jun. 2006.
} 
depois do internamento, foi constatado pela mãe da vítima, marcas de tortura, com as mãos amarradas, o nariz sangrando, rosto e abdômen inchados.

O Estado ficou inerte perante o pedido de esclarecimentos por parte da $\mathrm{CIDH}$.

No dia 22 de novembro de 1999, a Comissão acusou o recebimento da denúncia feita pela Sr. ${ }^{a}$ Irene Ximenes Lopes Miranda, havendo em 17 de fevereiro de 2000 o recebimento por parte da CIDH de informação adicional por parte da denunciante. Em $1^{\circ}$ de maio de 2000, a Comissão remeteu ao Estado outra nota pedindo-lhe que prestasse as informações necessárias no prazo de 30 dias, não havendo resposta por parte do Estado.

\section{Natureza das Violações}

A Comissão considera que prima facie os fatos alegados pela peticionaria podem vir a caracterizar violação à Convenção Americana nos seus artigos 4, 5, 11 e 25 por eventuais violações ao direito à vida, direito à integridade pessoal, proteção da honra e dignidade e direito a recurso judicial, todos em conexão com o dever genérico do Estado de respeitar e garantir os direitos como estabelecido no artigo 1.1. da Convenção Americana, em prejuízo do Sr. Damião Ximenes Lopes.

\section{Conclusão}

A Comissão conclui que é competente para tomar conhecimento deste caso e que a petição cumpre com os requisitos de admissibilidade, de acordo com os artigos 46 e 47 da Convenção Americana.

\subsection{Relatório 21/03 -Eldorado de Carajás - Petição 11.820}

Em 5 de setembro de 1996, o Movimento dos Trabalhadores Rurais sem Terra (MST) e o Centro pela Justiça e o Direito Internacional (CEJIL) apresentaram à Comissão Interamericana de Direitos Humanos uma petição contra a República Federativa do Brasil. A referida petição denuncia a violação dos artigos 4, 5, 8, 25 e 1.1. da Convenção Americana sobre Direitos Humanos, em prejuízo de Oziel Alves Pereira e outros.

Os peticionários alegam que em 17 de abril de 1996 o Estado brasileiro, por intermédio de seus agentes, assassinou 19 trabalhadores rurais e feriu dezenas deles, ao desalojá-los de uma rodovia pública, onde se encontravam acampados como parte de um grupo muito maior de trabalhadores.

Os peticionários salientam que no dia 17 de abril de 1996, aproximadamente às 16 horas, 155 policiais militares cercaram pelos dois lados um grupo de aproximadamente 
2181.500 trabalhadores rurais que se encontravam acampados na margem da rodovia estadual PA 150, no município de Eldorado dos Carajás, Estado do Pará.

Alegam que os policiais militares, após cercarem os trabalhadores pelos dois lados da rodovia, começaram a disparar contra eles. Salientam que, em virtude desses fatos, morreram 19 trabalhadores, 6 deles assassinados com os disparos iniciais e 13 executados sumariamente após a desobstrução da estrada, os quais não haviam podido fugir por se encontrarem feridos pelos mencionados disparos. Acrescentam que outros 69 trabalhadores foram gravemente feridos e dezenas de outros sofreram ferimentos leves.

\section{Conclusão}

A Comissão conclui que é competente para tomar conhecimento desta petição e que a mesma atende aos requisitos de admissibilidade, de acordo com os artigos $46 \mathrm{e}$ 47 da Convenção Americana.

\subsection{Relatório 40/03 - 42 ${ }^{\circ}$ Distrito Policial de São Paulo - Parque São Lucas}

\section{Caso 10.301}

\section{Vítimas}

01. Arnaldo Alves de Souza

02. Antônio Permoniam Filho

03. Amaury Raymundo Bernardo

04. Tomaz Badovinac

05. Izac Dias da Silva

06. Francisco Roberto de Lima

07. Romualdo de Souza

08. Wagner Saraiva

09. Paulo Roberto Jesuíno

10. Jorge Domingues de Paula

11. Robervaldo Moreira dos Santos

12. Ednaldo José da Fonseca

13. Manoel Silvestre da Silva

14. Roberto Paes da Silva

15. Antônio Carlos de Souza

16. Francisco Marlon da Silva Barbosa

17. Luiz de Matos

18. Reginaldo Avelino de Araújo 


\section{Histórico}

A denúncia alega que em 5 de fevereiro de 1989 ocorreu uma tentativa de motim nas celas do $42^{\circ}$ Distrito Policial do Parque São Lucas, na Zona Leste de São Paulo. Declara ainda que, com o intento de prevenir distúrbios, cerca de 50 detentos foram encarcerados em uma cela forte de um metro por três, dentro da qual foram jogados gases lacrimogêneos, e que 18 dos detentos morreram por asfixia e 12 foram hospitalizados.

O centro de detenção, que tem capacidade para 32 pessoas em quatro celas, alojava naquele momento - segundo consta da denúncia - 63 detentos.

Policiais civis envolvidos no caso do Parque São Lucas:

- Dr. Carlos Eduardo Vasconcelos - Delegado de Polícia Titular do 42 D.P./SP.

- Dr. Celso José da Cruz - Investigador de Polícia que estava no comando no momento da chacina.

- José Ribeiro - Carcereiro.

\section{Conclusão}

Tivemos a grata satisfação de escrever algumas linhas sobre a atuação da Comissão Interamericana de Direitos Humanos no Brasil, pois entendemos que muitas vezes os cidadãos desconhecem que possuem em seu favor um poderoso instrumento de proteção de suas garantias individuais.

É possível observarmos, com a leitura atenta dos casos de Eldorado de Carajás e dos presos mortos no interior da carceragem do $42^{\circ}$ Distrito Policial de São Paulo Parque São Lucas, que na maioria das vezes os autores das violações dos Direitos Humanos são agentes do Estado, pagos para proteger a Sociedade e não para violentála em sua dignidade.

Devemos destacar que após o processo de redemocratização do Brasil, o nosso país passou a ratificar tratados internacionais de proteção aos Direitos Humanos, o que no período de ditadura militar não se fazia, por motivos óbvios.

Sabemos que, ao se ratificar um Tratado Internacional referente aos Direitos Humanos, o país signatário se submete aos rigores decorrentes do referido tratado, exigindo-se, portanto, transparência nas apurações dos casos levados ao conhecimento da comunidade internacional, o que no caso do Brasil demonstra o grau de maturidade em relação aos Direitos Humanos.

Merece destaque o Relatório n. 38/02 - Damião Ximenes Lopes, visto que recentemente os jornais de grande circulação noticiaram que o Estado Brasileiro foi condenado a pagar vultosa quantia à família da vítima, como forma de indenização. 

tiveram início em sólidos alicerces, que no caso do Brasil, nunca poderá ser dissociado do respeito aos Direitos Humanos.

\section{Referências}

BOBBIO, Norberto; LAFER, Celso (apresentação). A Era dos Direitos. Rio de Janeiro: Campus. $2^{a}$ tiragem.

CENTRO DE ESTUDOS DA PROCURADORIA GERAL DO ESTADO DE SÃO PAULO. Sistema Interamericano de Proteção dos Direitos Humanos - Legislação e Jurisprudência. São Paulo, 2006.

COMISSÃO INTERAMERICANA DE DIREITOS HUMANOS (on line). Disponível na internet: http://cidh.org.org.

MAZZUOLI, Valério de Oliveira (organizador). Coletânea de Direito Internacional. São Paulo: Revista dos Tribunais, 2005.

MAZZUOLI, Valério de; GOMES, Luiz Flávio (prefácio). Tribunal Penal Internacional e o Direito Brasileiro. São Paulo: Premier Máxima, 2005.

O ESTADO DE SÃO PAUlO. Capa. Ano127. n. . 41.131, 29 de maio de 2006, segunda-feira.

PINHEIRO, Carla. Direito Internacional e Direitos Fundamentais. São Paulo: Atlas, 2001.

PIOVESAN, Flávia. STEINER, Henry (prefácio); TRINCADO, Antônio Augusto Cançado (apresentação). Direitos Humanos e o Direito Constitucional Internacional. São Paulo: Saraiva, 2006. $7^{\mathrm{a}}$ edição - revista, ampliada e atualizada. SORIANO, Aldir Guedes; BASTOS, Celso Ribeiro Bastos (prefácio); MAZZUOLI, Valério de Oliveira (apresentação). Liberdade Religiosa no Direito Constitucional e Internacional. São Paulo: Juarez de Oliveira, 2002. 